\title{
REVISTAMARACANAN
}

Dossiê

\section{Não somente indígenas como também africanos: uma introdução à demografia do Estado do Grão-Pará e Rio Negro (1778-1823)}

\author{
Not only Indians but also Africans: a first approach on the demography of the \\ State of Grão-Pará e Rio Negro (1778-1823)
}

\author{
Marcia Eliane Alves de Souza e Mello \\ Universidade Federal do Amazonas \\ marciamello64@yahoo.com.br
}

\author{
Daniel Souza Barroso \\ Universidade de São Paulo \\ dsbarroso@usp.br
}

\begin{abstract}
Resumo: Durante as últimas três décadas do século XVIII, foram produzidos vários mapas populacionais nas possessões portuguesas e espanholas na América. A preocupação com a estatística constituiu peça fundamental de uma nova arte de governar que se estabeleceu nesse contexto. A partir de dois mapas populacionais produzidos em 1778 e 1797 e de uma estatística demográfica coligida no limiar dos anos 1820, examinam-se, neste artigo, as transformações operadas no quadro demográfico do antigo Estado do Grão-Pará e Rio Negro. Para tal, o texto encontra-se estruturado em três seções. Na primeira delas, apresentam-se considerações gerais sobre as leituras clássicas acerca da formação econômica e social da Amazônia e o contexto de produção das estatísticas demográficas na região. $\mathrm{Na}$ segunda seção, analisam-se as transformações gerais no quadro demográfico daquele Estado. Na terceira e última, a partir de alguns estudos de casos, reduz-se a escala de observação e vislumbram-se essas transformações à luz de propriedades específicas.
\end{abstract}

Palavras-chave: Políticas de população; Estado do Grão-Pará e Rio Negro; Dinâmica demográfica.

\begin{abstract}
Throughout the last three decades of the 18th Century, several population maps were produced in the Portuguese and Spanish possessions in the Americas. Concern on the statistics constituted fundamental part of a new art of government that was established in that context. From two population maps produced in 1778 and 1797 and a demographic statistics collected on the threshold of the 1820s, we examine the transformations in the population structure and the demographic trends in the old State of Grão-Pará e Rio Negro. The text is structured into three sections. In the first one, we bring general remarks on the classic readings on economic and social formation of the Amazon and the context of production of the population maps in that region. In the second section, we analyze the general changes in the demographic structure of that state. In the third and last section, from a few case studies, we reduce the observation scale to see to those changes in the light of specific agrarian properties.
\end{abstract}

Keywords: Population policies; State of Grão-Pará e Rio Negro; Demographic dynamics. 


\section{História da Amazônia, história da população}

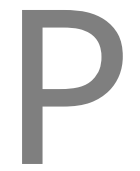

or longo tempo, foi lugar-comum na historiografia brasileira relacionar o processo de formação econômica e social da Amazônia à noção de "área periférica", constituída à margem dos diversos modelos explicativos da economia colonial na América portuguesa, elaborados a partir da década de 1940, por intelectuais como: Caio Prado Júnior, Nelson Werneck Sodré, Celso Furtado, Fernando Antonio Novais, Jacob Gorender e Ciro Flamarion Cardoso. Grosso modo, essa noção foi inoculada através de uma leitura embasada na experiência de colonização portuguesa no Atlântico Sul. Dito em outras palavras, o não enquadramento do antigo Estado do Grão-Pará e Rio Negro em um modelo explicativo da economia colonial que privilegiava as chamadas "áreas dinâmicas" (a exemplo do Nordeste açucareiro), contribuiu para que a Amazônia fosse classificada como "área periférica". Em vez de ser apreendida como um importante horizonte de comparação, aquela experiência foi apropriada como um modelo que se esperava reverberar no processo de colonização da região amazônica. ${ }^{1}$

Em certo sentido, a população serviu de alicerce para o argumento de que a Amazônia seria uma "área periférica", onde pretensamente a mão de obra escrava fora incipiente e uma economia de base agrícola não se efetivara. Essa ideia fortemente arraigada de que a economia da Amazônia colonial e imperial, de caráter fundamentalmente extrativista, havia sido suportada pela mão de obra indígena e, posteriormente, pela mão de obra de retirantes nordestinos, acabou relegando outras atividades econômicas e outras formas de trabalho a uma zona de opacidade na historiografia, relativizando a sua importância no funcionamento e na dinâmica da economia amazônica. No entanto, como estudos mais recentes evidenciam, os escravos negros não apenas figuraram, em determinadas conjunturas, enquanto uma parte expressiva da população da Amazônia, como também constituíram, até pelo menos os meados do século XIX, uma força produtiva de grande importância, sobretudo para a agricultura e a pecuária regionais. ${ }^{2}$

Se, por um lado, a população ajudou a sustentar a noção de "área periférica" atribuída à Amazônia por toda uma historiografia tradicional desde a década de 1940, por outro, estudos mais recentes em história da população e, em certa medida, em história da família, têm ajudado a questionar essa e muitas outras noções usualmente associadas à formação econômica e social da região. Nesse sentido, uma nova historiografia das formas familiares e da população na Amazônia vem representando outra plataforma de compreensão para a história regional em relação às suas próprias particularidades, ${ }^{3}$ sem que esse novo viés

\footnotetext{
${ }^{1}$ CHAMBOULeYRON, Rafael Ivan. Cacao, Bark-Clove, and Agriculture in the Portuguese Amazon Region in the Seventeenth and Early Eighteenth Century. Luso-Brazilian Review, Madison, 51(1), 2014. p. 2.

2 BEZERRA NETO, José Maia. Escravidão negra no Grão-Pará (séculos XVII-XIX). Belém: Paka-Tatu, 2012 [2001].

${ }^{3}$ Ver por exemplo: ÂNGELO, Helder Bruno Palheta. O longo caminho dos Corrêa de Miranda no século XIX: um estudo sobre família, poder e economia. Dissertação (Mestrado em História Social da Amazônia).
} 
implique, com efeito, perder de vista importantes perspectivas de comparação com as demais regiões do Brasil ou, mesmo, com outras regiões da Pan-Amazônia e da América Latina.

$\mathrm{Na}$ última década, os estudos sobre a Amazônia colonial portuguesa cresceram significativamente. Todavia, especificamente no caso da demografia histórica, ainda são necessárias mais investigações de caráter empírico que possam servir de base para novas análises. Não foi dada a devida atenção, por exemplo, às diferentes dinâmicas demográficas que vigoraram na Amazônia, tampouco foi empreendido um esforço mais substancial no sentido de evidenciar a possível existência de um ou mais regimes demográficos, à luz das especificidades que condicionaram a formação econômica e social da região. ${ }^{4}$ o desconhecimento mesmo de dados simples - como o tamanho real da população - remete alguns estudos a estimativas populacionais enviesadas, o que de certa forma compromete várias leituras sobre a dinâmica demográfica desse espaço ultramarino português.

Considerando as observações críticas assinaladas, propomos, neste artigo, uma abordagem ancorada no exame de diversos mapas estatísticos da população ordenados fazer pela Coroa portuguesa na região amazônica, na segunda metade do século XVIII, e numa estatística demográfica produzida em 1823. Em uma preliminar observação comparada dos dados pesquisados, visamos a analisar a dinâmica populacional de dois espaços geográficos do antigo Estado do Grão-Pará e Rio Negro - as capitanias do Pará e do Rio Negro - que possuíam características semelhantes no que diz respeito à sua formação histórica, mas, ao mesmo tempo, distintas no tocante às realidades econômicas - que viriam a influenciar a dinâmica demográfica das populações indígena e cativa, assim como a composição de cada um desses segmentos na força de trabalho de tais capitanias.

Ainda que os mapas populacionais aqui examinados já tenham sido parcialmente explorados pela historiografia amazônica, ${ }^{5}$ nenhum estudo se dedicou a analisá-los em perspectiva longitudinal - i.e., considerando as variações dos dados neles contidos ao longo do tempo -, de modo a observar a dinâmica populacional e as transformações no quadro demográfico do Estado do Grão-Pará e Rio Negro, na virada do século XVIII ao XIX. ${ }^{6}$ Essa lacuna é particularmente expressiva, na medida em que os mapas populacionais coligidos neste artigo e na historiografia que o precedeu, contemplam a multiplicidade de segmentos

Universidade Federal do Pará, 2012; SANTOS, Marília Cunha Imbiriba dos. Família, Trajetória e Poder no Grão-Pará Setecentista: os Oliveira Pantoja. Dissertação (Mestrado em História Social da Amazônia). Universidade Federal do Pará, 2015.

${ }^{4}$ Sobre o desenvolvimento da demografia histórica na Amazônia, ver: BARROSO, Daniel Souza. Por uma história da família e da população na Amazônia brasileira: percursos historiográficos. CICERCHIA, Ricardo et al. (Orgs.). Estruturas, conjunturas e representações: perspectivas de estudos das formas familiares. Múrcia: EDIT.UM, 2014. p. 51-66.

${ }^{5}$ Cf. KELLY-NORMAND, Arlene. Fontes primárias para a história de índios destribalizados na região amazônica. Boletim de Pesquisa do CEDEAM, Manaus, 5(8), jan./jun. 1986, p. 92-119; VIEIRA JUNIOR, Antonio Otaviano \& RAMOS, Ana Rita Oliveira. Guia de fontes para a História da População na Amazônia (1750-1800), v. 1. Belém: Editora Açaí, 2011; MELLO, Márcia Eliane de Souza e. Contribuição para uma demografia do Estado do Grão-Pará e Maranhão. 1774-1821. Anais de História de Além-Mar, Lisboa, 2015 - no prelo.

${ }^{6}$ Cf. BARROSO, Daniel Souza. Op. cit. 
sociais (inclusive os indígenas aldeados) existentes em todas as regiões do Estado do GrãoPará e Rio Negro - criando condições favoráveis, portanto, para uma observação mais pertinente do comportamento demográfico da Amazônia colonial, tendo em vista as diferentes realidades econômicas presentes na região e os distintos segmentos que conformam a sua população.

Desde a sua criação, no século XVII, até a adesão à independência em 1823, o Estado do Maranhão e suas capitanias subordinadas formaram uma unidade administrativa separada e independente do Estado do Brasil, reportando-se diretamente a Portugal. Durante o ministério pombalino, a região sofreu alguns reordenamentos administrativos e espaciais. Em 1751, foi criado o Estado do Grão-Pará e Maranhão, com sede administrativa em Belém - confirmando, dessa forma, a crescente preponderância da capitania do Pará sobre as demais capitanias existentes. Em 1774, ocorreu um novo desmembramento, desta vez criando dois espaços distintos, o Estado do Grão-Pará e Rio Negro e o Estado do Maranhão e Piauí, ambos subordinados à metrópole. ${ }^{7}$ No mapa abaixo (Figura 1), é possível vislumbrarmos o território compreendido pelo Estado do Grão-Pará e Rio Negro, com destaque para Belém (sua capital) e para as localidades do Acará e de Moju, objetos de nossa apreciação na última seção do texto.

\section{Figura 1}

TERRITÓRIO DO QUE VIRIA A SE TORNAR O ESTADO DO GRÃO-PARÁ E RIO NEGRO, COM DESTAQUE PARA AS LOCALIDADES DE BELÉM, ACARÁ E MOJU:

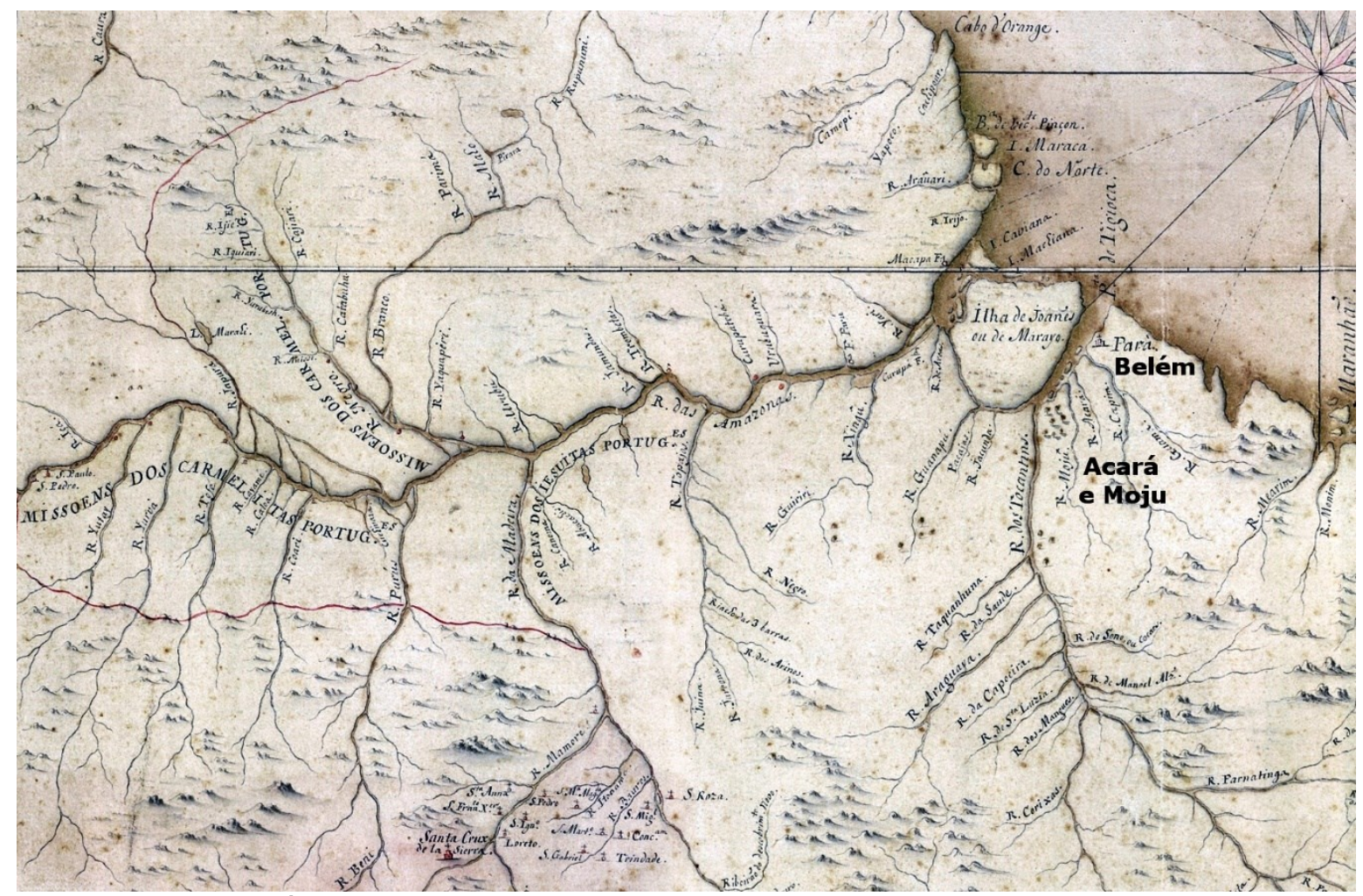

Fonte: CARVALHO, José Monteiro de. Mapa dos confins do Brasil, com as terras da Coroa de Espanha na América Meridional. 1752. Biblioteca Nacional de Portugal, Iconografia, Cota D 114-r.

\footnotetext{
7 SANTOS, Fabiano Vilaça dos. O governo das conquistas do Norte. São Paulo: Annablume, 2011. p. 3940.

8 O excerto recortado, correspondente ao território que viria se se tornar o Estado do Grão-Pará e Rio Negro em 1774, foi retirado do mapa referido que contempla grande parte do atual território brasileiro.
} 
Assim, a dinâmica de povoamento colonial foi diferenciada na região. ${ }^{9}$ Durante o período do Regimento das Missões (1686-1755), por exemplo, o território que ficou depois conhecido como capitania do Rio Negro (atual Amazonas) não podia ter povoações com moradores brancos, apenas aldeamentos de índios supervisionados por alguns missionários as chamadas "missões". ${ }^{10}$ Somente depois da criação da capitania, em 1755, surgiram os primeiros núcleos urbanos (vilas e lugares), ainda assim majoritariamente constituídos por uma população indígena, o que influenciou sobremaneira a sua demografia. ${ }^{11}$ Isso se observa claramente nos mapas de população do Rio Negro, onde existe uma forte desproporção entre as populações de índios, livres e cativos. Por outro lado, a capitania do Pará, mais desenvolvida economicamente em comparação à do Rio Negro, a partir de meados do século XVIII, tornou-se mais atrativa para imigrantes, com um fluxo constante de reinóis e pessoas de outras partes do Brasil, interessados no comércio e na agroindústria exportadora estimulada naquele período. Com o fim da escravidão indígena e a partir da criação da Companhia de Comércio do Grão-Pará e Maranhão (1755), a capitania paraense passou a receber também uma quantidade maior de cativos africanos.

Nesse sentido, a despeito das heterogeneidades econômicas internas das capitanias do Pará e do Rio Negro, é possível observarmos que ambas as capitanias possuíam estruturas econômicas, em sua essência, distintas. Se, por um lado, a capitania do Rio Negro ainda dependia fundamentalmente da coleta das drogas do sertão e assistia, como assinalamos acima, ao estabelecimento dos primeiros núcleos urbanos (vilas e lugares) habitados por moradores brancos, a capitania do Pará, por sua vez, apresentava uma economia mais diversificada e dinâmica. Para além da ainda importante coleta das drogas do sertão, o Pará experimentava, na segunda metade do século XVIII, o reposicionamento da agricultura em sua pauta de exportações. Produtos tais como o arroz e, em menor medida, o algodão, passaram a ser produzidos e exportados em volume cada vez maior; isso sem, entretanto, diminuir a importância relativa do cacau como o mais destacado produto de exportação da capitania do Pará. ${ }^{12}$

O Tratado de Madri, firmado em 1750, visava às demarcações dos limites dos domínios espanhóis e portugueses na América do Sul. Pautado pelo princípio da posse efetiva da terra utis possidetis -, conferia o direito à Coroa que houvesse ocupado antecipadamente o espaço

\footnotetext{
9 Cf. CHAMBouleYron, Rafael. Povoamento, ocupação e agricultura na Amazônia colonial (1640-1706). Belém: Editora Açaí, 2010.

10 Cf. MATTOS, Yllan de. Regimento das Missões do Estado do Maranhão e Grão-Pará, de 21 de dezembro de 1686: comentário. Revista 7 Mares, 01, 2012, p. 112-123.

11 Para se ter uma ideia do impacto deste tipo de povoamento, mais de 20 anos depois de extinto o Regimento das Missões, em 1778, o mapa de todos os habitantes do Estado apontava, na capitania do Pará, a existência de 53 povoações de índios e somente 19 povoações de brancos, enquanto na capitania do Rio Negro, todas as 37 povoações eram consideradas de índios. (Arquivo Histórico Ultramarino [AHU], Conselho Ultramarino, Pará, Cx. 85, doc. 6940. Carta do governador do Estado do Pará e Rio Negro João Pereira Caldas, para a rainha, D. Maria I, Pará, 29 de fevereiro de 1780).

12 Cf. ANDERSON, Robin Leslie. Colonization as Exploitation in the Amazon Rain Forest, 1758-1911. Gainesville, FL: University Press of Florida, 1999. p. 40-64.
} 
em disputa. Isso suscitou o interesse da Coroa portuguesa em criar uma nova política colonizadora capaz de corroborar sua autoridade na região. A população indígena passou a ser o elemento fundamental dessa política, compreendendo os índios como componente definidor das fronteiras coloniais e confirmador da ocupação lusitana. ${ }^{13}$ Assim sendo, a principal medida adotada para garantir esse processo foi a concessão da liberdade aos índios, em 1755, o que alterava o seu estatuto social, igualando-os aos demais vassalos do rei. ${ }^{14}$ Por intermédio de outras medidas - como o incentivo ao casamento misto, a obrigatoriedade do ensino da língua portuguesa, a transformação dos aldeamentos missionários em vilas e o incentivo à produção para o comércio - o elemento indígena foi sendo incorporado ao universo colonial. ${ }^{15}$

Em estudo recente, Mauro Coelho demonstrou a importância da edificação dos núcleos coloniais sob o controle metropolitano, a partir de meados do século XVIII, como parte do projeto de ampliação e consolidação do poder lusitano no Vale Amazônico. Desmitificando as novas medidas legais que abrangiam a população indígena nesse período, Coelho aponta que o forte interesse metropolitano na região - verificado em suas políticas reformadoras, que propunham civilizar a população indígena, ocupar o espaço e consolidar sua presença no território - deve ser compreendido em "função de um objetivo político que ultrapassava a questão indígena: tornar o Vale Amazônico parte do Império Português". ${ }^{16}$ Dessa feita, afirma o autor que embora a legislação indigenista tivesse as populações indígenas como objeto preferencial de sua ação, os seus objetivos eram mais amplos, buscando alcançar todos os habitantes do território.

Em 30 de setembro de 1772, em Lisboa, várias instruções régias foram passadas ao novo governador-geral do Grão-Pará, João Pereira Caldas, encaminhadas pelo secretário dos Negócios da Marinha e Ultramar, Martinho de Melo e Castro, as quais apontavam o novo sistema que se pretendia adotar na região para o seu desenvolvimento econômico. ${ }^{17} \mathrm{O}$ que nos interessa, aqui, é destacar o empenho metropolitano pela otimização dos recursos humanos disponíveis no estado e os mecanismos de controle idealizados pela metrópole sobre essa população, onde se incluem os recenseamentos sistemáticos que passaria a adotar.

As instruções afirmavam, no item 29, que "toda vantagem de um Estado consiste em destinar os seus habitantes ao serviço que lhes é mais próprio e natural, e mais conforme a

\footnotetext{
${ }^{13}$ Cf. FARAGE, Nádia. As muralhas dos sertões: Os povos indígenas no rio Branco e a colonização. Rio de Janeiro: Paz e Terra, 1991.

14 Para mais detalhes sobre esta legislação, ver: SOUZA, Robeilton. "Na forma que Sua Majestade permitir": a Lei de liberdade dos índios. Dissertação (Mestrado em História). Universidade Federal do Amazonas, Manaus, 2013.

15 COELHO, Mauro Cézar. Imenso Portugal: vilas e lugares no vale Amazônico. Revista Territórios e Fronteiras, 01(1), jan./jun. 2008. p. 270-71.

16 COELHO, Mauro Cézar. Op. cit., p. 264-5.

17 De acordo com Érika Dias, nos reinados de D. José I e D. Maria I, o Conselho Ultramarino "perdeu o seu papel de principal instituição central na mediação das disputas e na emanação de leis para o ultramar português. Passou a ser da secretaria a primazia na deliberação das matérias vindas das conquistas". DIAS, Érika de Almeida. "As pessoas mais distintas em qualidade e negócio": a Companhia de Comércio e as relações políticas entre Pernambuco e a Coroa no último quartel de Setecentos. Tese (Doutorado em História). Universidade Nova de Lisboa, Lisboa, 2014. p. 52.
} 
sua criação, força e possibilidade", ${ }^{18}$ sintetizando assim, o interesse metropolitano de interferir na forma como eram empregados os recursos humanos da colônia. Isso porque compreendia que os índios deveriam ser destinados às tarefas das coletas das drogas do sertão, enquanto os brancos e negros deveriam ser empregados em determinados serviços, como a agricultura e a pecuária.

Quando foi criado o Diretório dos Índios, em 1757, havia poucos cativos na capitania que pudessem cobrir a demanda dos serviços dos moradores. Para tanto, indicava o Diretório, no artigo 63, que os indígenas fossem repartidos da seguinte maneira: metade deles iria auxiliar os moradores das novas povoações em seus serviços e a outra metade ficaria para as suas manutenção e defesa. Contudo, passados alguns anos, tendo sido incentivada a entrada de imigrantes e introduzido um grande número de escravos africanos pela Companhia de Comércio, o plano metropolitano era maximizar o uso desses últimos no trabalho mais "pesado", para o qual os índios possuíam, alegadamente, menor resistência.

Dessa forma, os itens 32 e 33 das instruções ao governador alertavam que tivesse cuidado e fosse vigilante na repartição dos índios aos moradores, não os negando para os serviços dos sertões, mas que evitasse conceder os índios para os moradores utilizarem nas suas roças, plantações e engenhos de açúcar. O governador deveria "insinuar e persuadir aos ditos moradores, que os homens brancos e mais habitantes do Pará, que não tem de que vivam, e os negros introduzidos pela Companhia, são os mais próprios para o referido trabalho". ${ }^{19}$ Além disso, não deveria permitir que se empregassem os índios nos serviços que os brancos e negros poderiam fazer. Assim, sobrariam indígenas para ir ao sertão na coleta das drogas e para a execução do novo sistema que o governador deveria implantar a fim de dinamizar o comércio como o Mato Grosso. ${ }^{20}$

Em outubro de 1772, logo após essas instruções, foi expedida uma ordem régia ao mesmo governador tratando dos efetivos militares, na qual se ordenava que fossem enviados mapas particulares sobre o contingente. Na sequência, ordenava-se que fossem enviadas relações com número dos habitantes divididos em dez categorias. ${ }^{21} \mathrm{O}$ empenho de Pereira Caldas na formulação dos mapas de população foi notável. Tão logo assumiu o governo, em novembro de 1772, expediu uma circular aos párocos informando como deveriam proceder no levantamento das informações correspondentes às suas respectivas freguesias. ${ }^{22} \mathrm{~A}$ despeito dos inúmeros problemas ocorridos, como atrasos no envio dos dados e erros na confecção dos

\footnotetext{
18 AHU, Códice 596, fl. 5v-6.

19 AHU, Códice 596, fl. 6v.

20 O governador teria recebido instruções verbais sobre o assunto dadas pelo marquês de Pombal, em uma conferência na sua residência sobre a matéria, conforme afirma o item 35 da supracitada instrução.

21 Códice 596, fl. 19-21v, Ordem régia de 2 de outubro de 1772 ao governador João Pereira Caldas, na qual estabelecia a faixa etária para o levantamento da população masculina (0-7;7-15;15-60; acima de 60) e feminina ( $0-7 ; 7-14 ; 14-50$; acima de 50) e todos os nascimentos e mortes ocorridos no ano.

22 AHU, Conselho Ultramarino, Pará, Cx. 70, doc. 6002. (Ofício do governador João Pereira Caldas, para Martinho de Melo e Castro, Pará, 15 de maio de 1773).
} 
mapas parciais, foram produzidos, sob a sua administração, sete mapas anuais de população do Grão-Pará e do Rio Negro, compreendendo o período de 1773 a 1779.

Ao contrário do que imaginou a historiografia regional, o interesse da Coroa em conhecer os efetivos populacionais não se restringia somente ao Pará. Semelhantes ordens foram encaminhadas para outros domínios ultramarinos portugueses no mesmo período, o que sinaliza para uma nova política implementada durante o ministério pombalino, na qual a informação estatística e o conhecimento da população serviria como um instrumento para a administração. Como bem enfatizam Teodoro de Matos e Paulo Sousa, "a avaliação e contagem da população assumia uma importância crucial, servindo de suporte às políticas de ocupação do território, gestão das populações, exercício da fiscalidade, recrutamento militar e aproveitamento da mão de obra".23

Em 21 de maio de 1776, foi expedida uma nova ordem régia ao governador de Pernambuco, que estabelecia que as relações de habitantes deveriam ser enviadas anualmente para a Secretaria de Estado. Visando responder aos problemas observados na confecção dos mapas parciais, a ordem incumbia aos ministros da Justiça, assim como aos bispos, o auxílio aos governadores no levantamento exato da população, cumprindo, dessa maneira, as ordens reais "sobre um ponto de tanta importância como é o de saber S. Majestade o número de vassalos que habitam nos seus domínios". ${ }^{24}$ Foram dirigidas ordens idênticas às capitanias da Bahia, do Pará, de São Paulo e Minas Gerais, bem como aos governantes das Ilhas dos Açores e de São Tomé e Príncipe.

No mesmo ano, a Coroa espanhola expediu ordem similar aos seus governadores ultramarinos, solicitando informações sobre o número e a composição de seus vassalos na América e nas Filipinas, sendo que tais informações deveriam constar de raça, estado civil e qualidade de todas as pessoas de ambos os sexos e em todas as faixas etárias. ${ }^{25}$ Com efeito, nos anos seguintes foram produzidos vários documentos estatísticos para: Cuba (1777); Peru, Santiago do Chile e Buenos Aires (1778); Porto Rico e Quito (1780). ${ }^{26}$

Embora contemporâneas, as ordens emitidas pelas coroas ibéricas apresentam visíveis diferenças no seu conteúdo, como nos alertam Teodoro de Matos e Paulo Sousa. Enquanto a ordem espanhola solicitava vários dados sobre a população, particularmente sobre os distintos grupos sociais (brancos, negros, pardos, livres e escravos), a ordem portuguesa era omissa sobre esse aspecto, centrando-se somente nas faixas etárias e nos movimentos da população. Entretanto, a realidade da América portuguesa fez com que os governadores introduzissem novos elementos nos mapas, de acordo com sua região, particularmente os do Pará e Maranhão, em que foram incorporados os dados sobre os índios aldeados.

\footnotetext{
23 MATOS, Paulo Teodoro de \& SOUSA, Paulo Silveira. A estatística da população na América portuguesa, 1750-1820. Memorias, 25/04/2015. p. 75-76.

${ }^{24}$ AHU, Códice 583, fls. 173-173v.

25 ALDEN, Dauril. The Population of Brazil in the Late Eighteenth Century: A Preliminary Study. The Hispanic American Historical Review, 43(2), May/1963, p. 177.

26 MATOS, Paulo Teodoro de \& SOUSA, Paulo Silveira. Op. cit., p. 90.
} 
O governador do Estado do Pará e Maranhão, João Pereira Caldas, com base na ordem de 1772, já havia elaborado três modelos de mapas e encaminhado aos párocos das freguesias, a saber: Modelo 01: "Mapa de todos os habitantes índios, moradores adjuntos, escravos e fogos que existem na freguesia..."; Modelo 02: "Mapa de todos os habitantes e fogos presentes na freguesia..." com os dados das pessoas livres e escravas; Modelo 03: "Mapa de todos os habitantes que existem nas diferentes freguesias e povoações da capitania", composto das pessoas livres, índios aldeados e escravos. ${ }^{27}$ Não obstante a ordem expedida em 21 de maio 1776, que alterava a faixa etária feminina para 14-40 anos, Pereira Caldas não introduziu esta alteração nos mapas feitos no Pará e Rio Negro, mantendo os mesmos modelos da ordem de $1772 .{ }^{28}$

Tais modelos de cômputos de população do Pará e Rio Negro irão vigorar até 1797, quando nova ordem modificou substancialmente a natureza das informações estatísticas a serem encaminhadas ao Reino, em particular, o formato dos mapas de população. ${ }^{29}$ A ordem de 21 de outubro de 1797 determinava a produção de outros arrolamentos que implicavam a introdução de novos elementos. Os dados foram divididos em brancos, pretos e mulatos (livres e cativos), por sua vez repartidos em solteiros, viúvos e casados; passaram a ter a faixa etária dividia de cinco em cinco anos; e, para além dos nascimentos e das mortes, os levantamentos passaram a constar da presença dos casamentos ocorridos no decurso do ano civil, dando início à fase de aperfeiçoamento dos antigos recenseamentos brasileiros, que perduraria até 1830, quando os objetivos censitários passaram a ser "menos militares, e mais econômicos e de política populacional".30

\section{Evolução do quadro demográfico do Estado do Grão-Pará e Rio Negro (1778-1823)}

Os antigos mapas de população produzidos no Estado do Grão-Pará e Rio Negro nas últimas décadas do século XVIII, acompanhados de uma estatística produzida na então província do Pará - que abarcava a Comarca do Rio Negro -, no limiar da década de 1820,

\footnotetext{
${ }^{27} \mathrm{AHU}$, Conselho Ultramarino, Pará, Cx. 70, doc. 6002. (Ofício do governador João Pereira Caldas, para o secretário de Estado da Marinha e Ultramar, Martinho de Melo e Castro, Pará, 15 de maio de 1773).

${ }^{28} \mathrm{AHU}$, Conselho Ultramarino, Pará Cx. 76, doc. 6355 (Ofício do governador João Pereira Caldas, para o secretário de Estado da Marinha e Ultramar, Martinho de Melo e Castro, Pará, 8 de novembro de 1776).

29 Eram dez os mapas a serem confeccionados, a saber: 1) dos habitantes que existem na capitania, 2) das ocupações dos mesmos habitantes, 3) dos casamentos anuais, nascimentos e mortes, 4) da importação 5) da exportação 6) das produções da capitania, 7) dos preços correntes dos gêneros, 8) dos navios que entram e saem 9) declarando a povoação, casamentos, nascimentos, mortes dos índios domésticos e 10) uma tabela para se notarem as moléstias e casualidades que deram as ditas mortes. AHU, Conselho Ultramarino, Piauí, Cx. 21, doc. 1094 (Ofício do governador do Piauí D. João de Amorim Pereira, para o secretário de Estado da Marinha e Ultramar, D. Rodrigo de Sousa Coutinho, Oeiras do Piauí, 19 de agosto de 1798).

30 MARCÍLIO, Maria Luiza. Crescimento demográfico e evolução agrária paulista, 1700-1836. São Paulo: EDUSP/HUCITEC, 2000. p. 39.
} 
servem-nos de base para delinear a dinâmica geral da evolução demográfica da Amazônia no entresséculos. Tendo em vista a consistência do conjunto de mapas e estatísticas populacionais produzidos nessa região, lançamos mão de três deles para embasamento de nossas análises: o mapa de 1778 (produzido no primeiro ano após o monopólio da Companhia de Comércio do Grão-Pará e Maranhão), o de 1797 e a estatística reunida no Ensaio corográfico sobre a Província do Pará, referente a 1823, mas somente publicada em 1839. ${ }^{31}$ Por ter sido Antônio Baena, autor do Ensaio corográfico, o funcionário responsável pela organização estatística do Grão-Pará no alvorecer do Império, a sua estatística incorpora, como já se argumentou anteriormente, um caráter "semioficial". ${ }^{32}$ Na Tabela 1, apresentamos o quadro geral da população do Pará e do Rio Negro nos três anos de observação examinados $(1778,1797$ e 1823):

Tabela 1

População livre, indígena e escrava do Grão-Pará e do Rio Negro (1778-1823)

\begin{tabular}{|c|c|c|c|c|c|c|c|c|}
\hline & \multirow{2}{*}{ Ano } & \multicolumn{2}{|c|}{$\begin{array}{l}\text { Livres não } \\
\text { indígenas }\end{array}$} & \multicolumn{2}{|c|}{ Indígenas } & \multicolumn{2}{|c|}{ Escravos } & \multirow{2}{*}{ Total } \\
\hline & & $\mathbf{N}$ & $\%$ & $\mathbf{N}$ & $\%$ & $\mathbf{N}$ & $\%$ & \\
\hline \multirow{3}{*}{ 帛 } & 1778 & 23.668 & 43,1 & 19.179 & 34,9 & 12.067 & 22,0 & 54.914 \\
\hline & 1797 & 28.831 & 40,8 & 22.187 & 31,4 & 19.586 & 27,7 & 70.604 \\
\hline & 1823 & 79.376 & 60,6 & 22.620 & 17,3 & 29.015 & 22,1 & 131.011 \\
\hline \multirow{3}{*}{ 음 $\frac{0}{\frac{0}{0}}$} & 1778 & 979 & 8,7 & 9.975 & 88,8 & 280 & 2,5 & 11.234 \\
\hline & 1797 & 1.510 & 10,5 & 12.280 & 85,1 & 636 & 4,4 & 14.426 \\
\hline & 1823 & 8.750 & 46,4 & 9.131 & 48,5 & 962 & 5,1 & 18.843 \\
\hline \multirow{3}{*}{$\begin{array}{l}\bar{\nwarrow} \\
\stackrel{0}{\circ}\end{array}$} & 1778 & 24.647 & 37,3 & 29.154 & 44,1 & 12.347 & 18,7 & 66.148 \\
\hline & 1797 & 30.341 & 35,7 & 34.467 & 40,5 & 20.222 & 23,8 & 85.030 \\
\hline & 1823 & 88.126 & 58,8 & 31.751 & 21,2 & 29.977 & 20,0 & 149.854 \\
\hline
\end{tabular}

Fontes: Arquivo Histórico Ultramarino (AHU). Pará (Avulsos), cx. 85, doc. 6940 (1778); Arquivo Nacional (AN/RJ). Códice 99, vol. 19, fl. 50 (1797); BAENA, Antônio Ladislau Monteiro. Ensaio corográfico sobre a província do Pará. Brasília: Senado Federal, Conselho Editorial, 2004 [1839], p. 260-348 (1823).

Os dados compilados (Tabela 1) evidenciam a existência de marcantes diferenças entre a composição demográfica do Pará e a do Rio Negro. Além de a população daquela capitania ter sido substancialmente maior que a população desta nos três anos coligidos, podemos notar também que as suas composições em função dos três segmentos considerados (livres não indígenas, indígenas e escravos) eram fundamentalmente distintas. No Pará, observarmos a existência de uma população com maioria relativa livre e com maior participação relativa de escravos, sem embargo à manutenção do contingente indígena na população da capitania, entre 1778 e 1823. No caso do Rio Negro, cujo povoamento - como destacamos antes contava inicialmente apenas com missionários e indígenas, verificamos uma população, em sua maioria, autóctone e com um diminuto contingente de escravos, não obstante uma

31 BAENA, Antônio Ladislau Monteiro. Ensaio corográfico sobre a Província do Pará. Brasília: Senado Federal, Conselho Editorial, 2004 [1839].

32 BARROSO, Daniel Souza. Op. cit., p. 55. 
participação relativa pequena, mas crescente, do segmento livre não indígena em sua composição demográfica, especialmente entre os anos de 1797 e 1823.

Em termos gerais, apesar da tendência crescente dos segmentos livre não indígena e escravo (este especialmente no caso do Pará) em ambas as regiões consideradas, parece-nos claro ter havido igualmente uma manutenção relativa do contingente indígena tanto do Pará quanto do Rio Negro, mesmo em um contexto de gradual assimilação dos indígenas à sociedade colonial - o que pode ter levado à sua parcial diluição no segmento livre não indígena arrolado nos mapas de população e na estatística produzida por Antônio Baena. A absorção do elemento indígena à população livre, ainda que difícil de estimar com precisão, é um elemento que precisa ser sempre vislumbrado nas análises sobre a população da Amazônia colonial, por conta de seu elevado potencial de enviesamento dos contingentes livre não indígena e indígena de tal população. Causa estranheza, por exemplo, que na Barra do Rio Negro (hoje Manaus), para além dos livres não indígenas e dos cativos, não tenha sido catalogado sequer um indígena em si, mas apenas caboclos ("mamelucos", "baços" e "mestiços"). ${ }^{33}$ Ressalva feita, passamos à análise dos ritmos de crescimento demográfico do Pará e do Rio Negro.

Tabela 2

Taxas médias geométricas de crescimento anual da população (\%) por regiões (Grão-Pará e Rio Negro, 1778-1823)

\begin{tabular}{ccccccccc}
\hline & \multicolumn{2}{c}{ Livres não } & \multicolumn{2}{c}{ Indígenas } & \multicolumn{2}{c}{ Escravos } & \multicolumn{2}{c}{ Geral } \\
\cline { 2 - 9 } Capitanígenas & $\mathbf{1 7 7 8 -}$ & $\mathbf{1 7 9 7 -}$ & $\mathbf{1 7 7 8 -}$ & $\mathbf{1 7 9 7 -}$ & $\mathbf{1 7 7 8 -}$ & $\mathbf{1 7 9 7 -}$ & $\mathbf{1 7 7 8 -}$ & $\mathbf{1 7 9 7 -}$ \\
& $\mathbf{1 7 9 7}$ & $\mathbf{1 8 2 3}$ & $\mathbf{1 7 9 7}$ & $\mathbf{1 8 2 3}$ & $\mathbf{1 7 9 7}$ & $\mathbf{1 8 2 3}$ & $\mathbf{1 7 9 7}$ & $\mathbf{1 8 2 3}$ \\
\hline Grão-Pará & $+1,04$ & $+3,97$ & $+0,77$ & $+0,07$ & $+2,58$ & $+1,52$ & $+1,33$ & $+2,41$ \\
Rio Negro & $+2,31$ & $+6,99$ & $+1,10$ & $-1,13$ & $+4,41$ & $+1,60$ & $+1,32$ & $+1,03$ \\
\hline Total & $+1,10$ & $+4,19$ & $+0,88$ & $-0,32$ & $+2,63$ & $+1,53$ & $+1,33$ & $+2,20$ \\
\hline
\end{tabular}

Fontes: Arquivo Histórico Ultramarino (AHU). Pará (Avulsos), cx. 85, doc. 6940 (1778); Arquivo Nacional (AN/RJ). Códice 99, v. 19, fl. 50 (1797); BAENA, Antônio Ladislau Monteiro. Ensaio corográfico sobre a província do Pará. Brasília: Senado Federal, Conselho Editorial, 2004 [1839], p. 260-348 (1823).

As taxas médias geométricas de crescimento anual das populações do Pará e do Rio Negro (Tabela 2) mostram que, apesar de tais regiões terem apresentado taxas de crescimento praticamente idênticas (1,33\% a.a. no Pará e 1,32\% a.a. no Rio Negro) entre 1778 e 1797, na virada do século XIX até 1823, a população do Pará cresceu a um ritmo mais acelerado (2,41\% a.a.) que a população do Rio Negro (1,03\% a.a.). Mesmo que as taxas de crescimento dos segmentos livre não indígena e escravo do Rio Negro tenham sido maiores que as taxas correlatas para o Pará em ambos os intervalos considerados (1778-1797 e 17971823), as dessemelhantes composições demográficas do Pará e do Rio Negro levaram aquela região a apresentar taxas maiores de crescimento entre 1797 e 1823 . Isso pois, em que pese o fato de os crescimentos dos segmentos livre não indígena e cativo da população do Rio

33 BAENA, Antônio Ladislau Monteiro. Op. cit., p. 290. 
Negro terem sido mais expressivos que os do Grão-Pará, o principal segmento demográfico (indígenas) do Rio Negro passou a apresentar taxas de crescimento negativo de $-1,13 \%$ a.a., entre de 1797 e 1823.

Não obstante uma ligeira involução demográfica do segmento indígena da população do Rio Negro, entre 1797 e 1823, e a menor expressividade de sua população (mesmo do próprio segmento indígena) em relação à do Pará, é possível notarmos o efeito da política metropolitana na promoção do crescimento demográfico do Estado do Grão-Pará e Rio Negro, através do incentivo à imigração, do fomento ao tráfico de cativos (mesmo no contexto posterior àquele do monopólio da Companhia de Comércio do Grão-Pará e Maranhão) e da manutenção do segmento indígena, que continuava a constituir uma fração importante da população e da força de trabalho da Amazônia entre 1778 e 1823 (Tabela 1). A despeito da relativa manutenção do contingente indígena em ambas as regiões e, consequentemente, da conservação de sua importância como força de trabalho, não há como colocarmos em xeque uma tendência a um rearranjo da composição demográfica do Pará e do Rio Negro, que, como apontamos anteriormente, passava tanto pela imigração de portugueses reinóis e insulares quanto pelo estímulo ao trato de escravos.

Não dispomos de dados sobre a imigração portuguesa para a Amazônia colonial, mesmo que saibamos ter existido um importante esforço em promover a imigração de açorianos para a região. ${ }^{34}$ Por outro lado, estimativas mais recentes embasadas nos dados disponíveis na Trans-Atlantic Slave Trade Database dão conta de que entre 1751 e 1787, período que cobre o monopólio da Companhia de Comércio (1755-1778) além de anos anteriores e posteriores, ingressaram 22.481 escravos no Grão-Pará e no Rio Negro; a maioria deles se estabeleceu no Pará. Já entre 1788 e 1815, estima-se que 17.072 escravos ingressaram nessas regiões, nos mesmos termos explicitados anteriormente. ${ }^{35}$ Ainda que o fato de não dispormos dos dados primários a respeito do tráfico e a existência de um desvio-padrão, provavelmente elevado, imponham limites à análise ora em questão, a partir do recurso das médias, é possível notarmos que não houve alteração expressiva no volume de escravos ingressados no Pará nos dois períodos contemplados: entre 1751 e 1787 entraram, em média, 607,6 escravos/ano e, entre 1788 e 1815, em média, 609,7 escravos/ano.

Se considerarmos, no caso específico do Pará, os intervalos de 1778 a 1797 e de 1797 a 1823, observaremos que as taxas médias anuais de crescimento de sua população escrava foram de 2,58\% a.a. e 1,52\% a.a., respectivamente. Confrontando tais taxas a sua correspondente para 25 localidades de diferentes regiões paulistas entre 1777 e 1829, aferida

\footnotetext{
34 Sobre a e/migração de portugueses para a Amazônia, ver especialmente: COSME, João dos Santos Ramalho. A emigração portuguesa para o Brasil na $2^{a}$ metade do século XVIII. Lição (Agregação em História Regional e Local). Universidade de Lisboa, Lisboa, 2007.

35 HAWTHORNE, Walter. From Africa to Brazil: Culture, Identity, and an Atlantic Slave Trade, 1600-1830. Cambridge: Cambridge University Press, 2010. p. 52-53.
} 
por Francisco Vidal Luna em 2,19\% a.a., ${ }^{36}$ entrevemos que o ritmo de crescimento da população cativa de São Paulo (1777-1829), mesmo que superasse o da escravaria paraense entre 1797 e 1823, era por certo inferior ao ritmo de crescimento da escravaria paraense entre os anos de 1778 e 1797. Das distintas regiões de São Paulo observadas por Luna, somente as escravarias do Oeste Paulista e do Vale do Paraíba apresentaram taxas médias de crescimento anual superiores às da escravaria paraense, entre 1778 e 1797, de, respectivamente, 3,86\% a.a. e $2,88 \%$ a.a. ${ }^{37}$

Embora as últimas décadas do século XVIII assistam ao início do processo de crioulização da população escrava da Amazônia, fruto de sua própria reprodução endógena e da miscigenação com outros segmentos que compunham a população da região, a política de fomento ao tráfico de escravos direcionado ao Estado do Grão-Pará e Rio Negro, muito mais efetiva na capitania do Pará, contribuiu para o estabelecimento de um expressivo número de cativos na região, acarretando uma profunda transformação da composição demográfica e da estrutura da força de trabalho na região. Se até a criação da Companhia de Comércio do GrãoPará e Maranhão o segmento indígena afigurou como alicerce fundamental da estrutura produtiva da Amazônia, depois da criação dessa Companhia, da dissolução de seu monopólio (1778) e de sua dissolução total (1788), o segmento cativo passou a constituir, especificamente no caso do Pará, um segundo alicerce fundamental da estrutura produtiva da região, ao lado do segmento indígena. A estrutura produtiva do Rio Negro, por sua vez, permaneceu esteada basicamente na mão de obra indígena, em que pese o expressivo crescimento do segmento livre não indígena em sua população, como sugerem os dados (Tabela 1 e Tabela 2).

Além de evidenciar o expressivo incremento da população livre não indígena do Pará, entre 1797 e 1823, o desenho (Gráfico 1) evidencia claramente a consolidação dos escravos como o segundo alicerce fundamental da estrutura produtiva do Pará (entre 1797 e 1823, o número de escravos inclusive superou o de indígenas na população paraense) e o aumento do número de livres não indígenas do Rio Negro, que passou a ombrear com o contingente indígena existente nessa comarca, em 1823. Ademais, a representação gráfica das populações do Pará e do Rio Negro demonstra uma manifesta predominância da população do Pará sobre a população do Rio Negro, em todos os três períodos de observação (1778, 1797 e 1823) e em relação a todos os segmentos (livres não indígenas, indígenas e escravos) considerados para fins de análise.

\footnotetext{
36 LUNA, Francisco Vidal. São Paulo: população, atividades e posse de escravos em vinte e cinco localidades (1777-1829). LUNA, Francisco Vidal et al. (Orgs.). Escravismo em São Paulo e Minas Gerais. São Paulo: EDUSP/Imprensa Oficial do Estado de São Paulo, 2009. p. 339.

37 Id.
} 


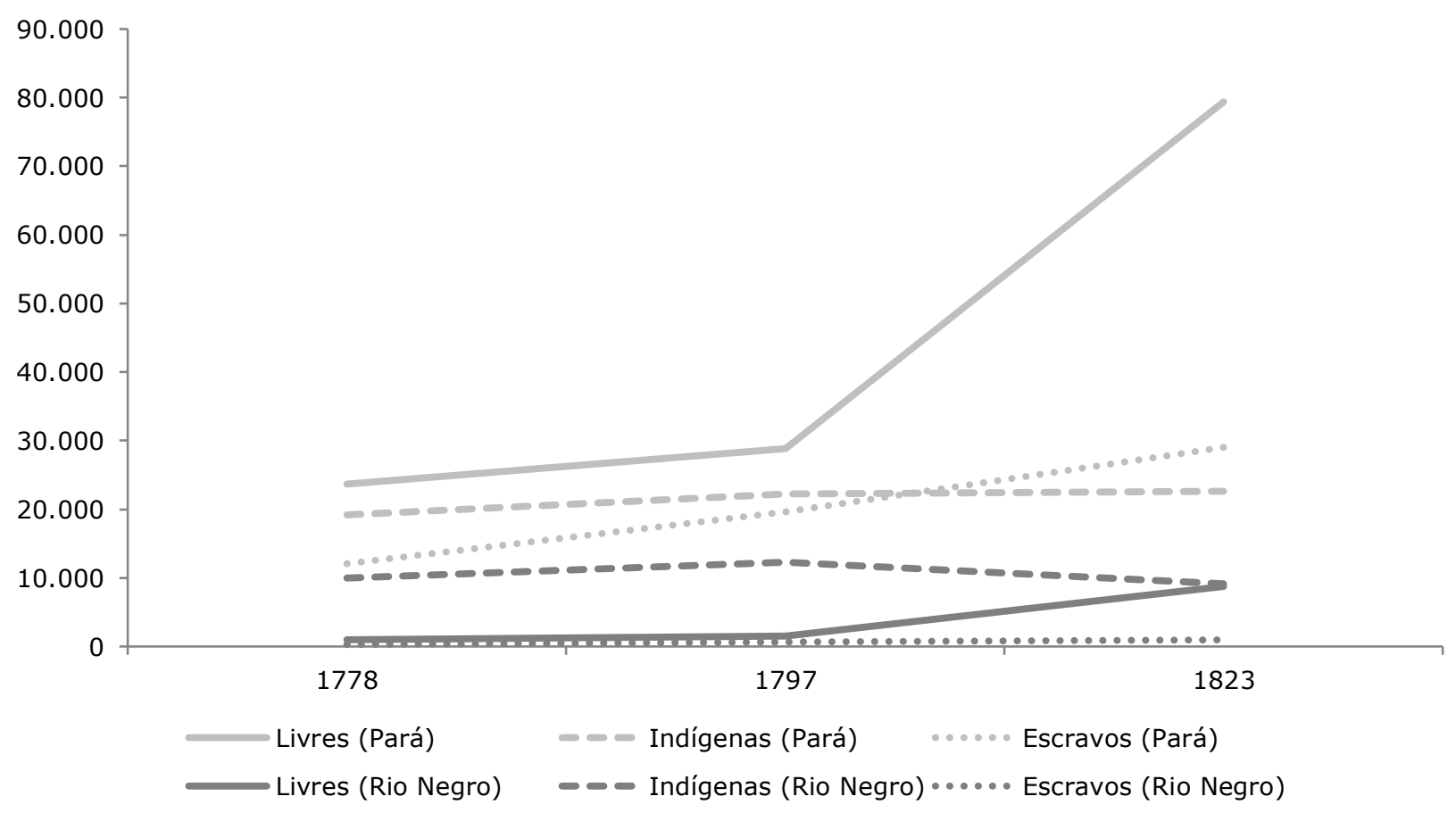

Fontes: Arquivo Histórico Ultramarino (AHU). Pará (Avulsos), cx. 85, doc. 6940 (1778); Arquivo Nacional (AN/RJ). Códice 99, v. 19, fl. 50 (1797); BAENA, Antônio Ladislau Monteiro. Ensaio corográfico sobre a província do Pará. Brasília: Senado Federal, Conselho Editorial, 2004 [1839], p. $260-348$ (1823).

Em resumo, podemos concluir que a despeito da efetividade da política metropolitana em promover a imigração de portugueses reinóis e insulares e o tráfico de escravos africanos (este, mais representativo no Pará) para a região compreendida no antigo Estado do GrãoPará e Rio Negro, em momento nenhum os indígenas deixaram de representar um importante segmento da população e, consequentemente, um alicerce fundamental da estrutura produtiva de ambas as regiões, ainda que em coexistência, no caso do Grão-Pará, com uma crescente (em importância) mão de obra escrava. De forma a afunilarmos a nossa compreensão do rearranjo demográfico e econômico indicado nas últimas páginas e também como modo de estreitarmos os limites entre os indivíduos e a sociedade, passamos agora à análise de alguns estudos de caso que nos permite observar tais movimentos mais amiúde.

\section{Esmiuçando o quadro geral da demografia do Estado do Grão-Pará e Rio Negro}

Após observamos as tendências globais apontadas nos mapas populacionais analisados anteriormente, em particular na capitania do Pará, em que são notáveis o peso das povoações indígenas e o contínuo incremento da população escrava, faz-se necessária uma análise mais circunstanciada dessa dinâmica. Para tanto, optamos por nos concentrar na parte final deste ensaio, observar os efeitos mais pormenorizados dessa dinâmica populacional, entre 1778 e 
1797, na região do Acará e do Moju, por serem os principais núcleos agrários da capitania. Isso sem perder de vista, naturalmente, as políticas governamentais de controle demográfico que iam sendo ditadas pelas circunstâncias impostas pelo projeto metropolitano.

As localidades do Acará e do Moju (Figura 1) estavam situadas no chamado Baixo Tocantins. Após a introdução de um expressivo contingente de cativos na capitania por meio da Companhia de Comércio do Grão-Pará e Maranhão, o Baixo Tocantins se moldou como talvez o mais importante reduto escravista do Grão-Pará sete-oitocentista. A região, onde se destacavam as localidades do Acará e do Moju, formava um complexo econômico votado ao extrativismo do cacau "bravo", à produção da cana-de-açúcar e derivados e à agricultura de gêneros diversos (cacau "manso", mandioca, arroz, algodão etc.). ${ }^{38}$

Em 1780, José de Nápoles Teles de Menezes, ao assumir o governo do Estado do Pará e Rio Negro, traçou um plano de ação visando a impulsionar as exportações com o incentivo ao plantio de arroz. Teles de Menezes também procurou dinamizar o comércio interno promovendo o incremento da cultura do açúcar, visto vez que a produção do gênero, na capitania, era insuficiente mesmo para atender a sua própria demanda interna pelo produto. ${ }^{39}$ Para tanto, o governador acionou a Câmara de Belém, que expediu uma carta circular aos senhores de engenhos reais do distrito da cidade, em 11 de setembro de 1780, na qual solicitava informações sobre as condições em que se encontravam os utensílios dos engenhos, a utilização de cativos e indígenas nas suas lavouras e, ainda, que apontassem as suas necessidades para fazer frente a uma produção que seria preestabelecida pela Câmara anualmente. ${ }^{40}$

Com a extinção do monopólio da Companhia de Comércio (1778), os senhores de engenho paraenses passaram a sofrer penhoras e execuções de seus bens e escravos, por serem devedores da própria Companhia. Tal situação teria agravado as condições de produção dos engenhos por falta de operários suficientes para lavrar as plantações. Os senhores de engenho da capitania recorreram ao rei solicitando que lhes fossem concedidos também os privilégios e as isenções outorgados aos senhores de outras capitanias, para que assim pudessem continuar com a fabricação do açúcar. ${ }^{41}$ Foi nesse contexto que as respostas dos senhores de engenho submetidas à Câmara, em novembro de 1780, expunham como principal razão para a improdutividade da lavoura canavieira a falta de mão de obra. De modo a equacionar tal problema os senhores de engenho argumentavam que a solução para o mesmo seria a concessão de um número expressivo de índios que pudessem trabalhar nos engenhos.

\footnotetext{
38 Cf. ANDERSON, Robin Leslie. Op. cit., p. 40-64; BARROSO, Daniel Souza. Coletando o cacau "bravo", plantando o cacau "manso" e outros gêneros: um estudo sobre a estrutura da posse de cativos no Baixo Tocantins (Grão-Pará, 1810-1850). XIX Encontro Nacional de Estudos Populacionais, São Pedro, 2014, p. 5.

${ }^{39}$ Biblioteca da Ajuda, Manuscrito 54, XI, 27 (17). Memória de todas as pessoas que desde o princípio da conquista governaram as duas capitanias do Maranhão e Grão-Pará 1613-1787.

40 AHU, Conselho Ultramarino, Pará, Cx. 89, doc. 7231. (Carta do ouvidor-geral da capitania do Pará, Matias José Ribeiro, para o secretário Martinho de Melo e Castro, Pará, 03 de setembro de 1782).

41 AHU, Conselho Ultramarino, Pará, Cx. 82, doc. 6736. (Consulta do Conselho Ultramarino, Lisboa, 04 de março de 1779).
} 
Com efeito, Teles de Menezes, após ter ciência de que havia um grande número de índios que vagavam sem domicílio, passou a conduzi-los às povoações do Estado com o auxílio de escoltas militares. E, para colocar em prática seu plano de dinamizar a produção agrícola, passou a conceder, através de portarias, mais indígenas para os moradores aplicarem nas suas diferentes culturas e para outros serviços. ${ }^{42}$ Entretanto, não se registra, nesse período, qualquer enumeração feita por ordem de Teles de Menezes para que possamos observar melhor esse incremento sugerido pelo governador em correspondência ao Reino.

No entanto, o seu antecessor, Pereira Caldas, deixou-nos um precioso mapa das famílias do Pará, realizado em 1778, no qual são indicados nominalmente os cabeças de família, acompanhados do número de pessoas de que a família se compunha, incluindo os escravos e as pessoas que trabalhavam por salários. O mapa apresenta, portanto, uma leitura ampla da estrutura domiciliar do Pará elidindo apenas os indígenas aldeados. ${ }^{43}$ Lançamos mão desse mapa nominal para contrastar as informações mencionadas nas cartas dos senhores de engenho para a Câmara, observando, como já explicitamos, as freguesias do Acará e Moju.

Segundo o mapa de famílias de 1778, Acará e Moju tinham, respectivamente, 61 e 123 chefes de famílias. Enquanto os chefes de família do Acará reuniam 210 índios em soldada e 575 cativos africanos, os de Moju reuniam 345 índios em soldada e 876 cativos africanos. Considerando o conjunto da força de trabalho de ambas as localidades analisadas, percebemos que $72,3 \%$ do efetivo de mão de obra dessas localidades (não incluindo os livres não indígenas) era constituído por escravos africanos. Caso consideremos duas categorias específicas dos chefes de família (senhores de engenhos e engenhocas vis-à-vis os lavradores), observaremos variações nos pesos relativos de indígenas e africanos na composição da força de trabalho por atividades econômicas. Nas propriedades dos senhores de engenhos e engenhocas de ambas as localidades (26 chefes de família ao todo), havia uma proporção de praticamente um indígena (236 ao todo) para cada três escravos africanos (751 ao todo). Já nas propriedades dos lavradores, a proporção correspondente era de cerca de um indígena (276 ao todo) para cada dois escravos africanos (510 ao todo).

Observando mais detalhadamente os proprietários com maior efetivo de índios, em soldada, no Acará, encontramos o mestre de campo Pedro Siqueira de Queirós, senhor de engenho, com 33 índios em soldada e 15 escravos, seguido do lavrador Lourenço Gonçalves de Andrade, com 26 índios e dois escravos. Enquanto no rio Moju o maior número de índios em soldada se encontrava na propriedade do senhor de uma engenhoca, Hilário de Morais Bittencourt, com 48 índios e 60 escravos, seguido do senhor de engenho João Ferreira Ribeiro, com 33 índios e 70 escravos, que eram também os maiores proprietários de escravos do Moju, seguidos pelo lavrador Agostinho de Gusmão, com 22 índios e 24 escravos. Em contrapartida,

\footnotetext{
42 Arquivo Público do Estado do Pará [APEP], Códice 359, cartas enviadas à metrópole, Pará, 17 de janeiro de 1781 .

43 AHU, Conselho Ultramarino, Pará, Cx. 94, doc. 7509. (Carta do governador do Estado do Pará e Rio Negro, João Pereira Caldas, para o secretário de Estado, Martinho de Melo e Castro, Barcelos, 22 de junho de 1785).
} 
no Acará, D. Francisca Xavier de Siqueira, senhora de engenho, que era a maior proprietária de escravos, com 87 cativos, tinha somente 10 índios em soldada.

O que nos indicam claramente estes dados de 1778 ? Em primeiro lugar, que a utilização de índios em soldada na agricultura era uma prática que se manteve, a despeito das instruções passadas ao govenador Pereira Caldas, em 1772, para que priorizasse o uso dos índios cedidos aos moradores para as atividades de coleta de drogas. E, em segundo lugar, que havia plantéis com número expressivo de escravos não apenas entre os senhores de engenho, mas também entre os lavradores.

Na correspondência encaminhada à Câmara de Belém podemos observar que, entre os discursos justificadores da baixa produtividade do açúcar, também existe uma deliberada omissão de informação por parte de alguns proprietários sobre o real efetivo de seus trabalhadores, ${ }^{44}$ embora tenham todos como denominador comum o pedido para maior concessão de índios, como podemos notar no caso de João Rodrigues de Castro, cujo engenho real no Acará, em 1778, apontava a presença de 33 índios em soldada e 15 escravos. Entretanto, na sua resposta à Câmara, sinalizava que não tinha mais que "11 escravos e 3 livres concedidos por portaria do governador", mas que tendo os sujeitos hábeis e com força para aguentar o trabalho "poderia abundar a cidade com mais açúcar do que faço se tivera mais operários". ${ }^{45}$

Em contrapartida, outro senhor de engenho no Acará, o sargento-mor Carlos Gemaque de Albuquerque, considerado no mapa de 1778 ser de mediana possibilidade, não havia indicado nele nenhum índio em soldada. Todavia, em sua correspondência de 1780, afirmava que havia recebido cinco índios por portaria do governador, mas que eram insuficientes para a produção que seu engenho poderia fazer. E se o governador lhe concedesse "todos os anos nos meses de julho, agosto, setembro e outubro com 40 pessoas de trabalho, sendo 30 índios e 10 índias para o dito ministério de fabricar açúcar", ${ }^{46}$ poderia fazer as arrobas de açúcar que Ihe fossem determinadas pela Câmara.

O emprego dos índios se fazia necessário para várias atividades, e por ser o trabalho nos canaviais muito pesado, as atividades se distribuíam de acordo com suas condições físicas, bem como a quantidade de operários. Assim é que José Landi, proprietário de engenho perto da cidade, informava que para ajudar nos quatro meses de roça e encoivara, necessitava da concessão de 20 índios, enquanto a plantação faria com os operários de que já dispunha, que

\footnotetext{
44 Não seria por acaso que o teor das repostas do mestre de campo João Ferreira Ribeiro, sua mãe D. Ângela de Oliveira Franca, o mestre de Campo Pedro de Siqueira Queirós e Amândio José de Oliveira Pantoja (em nome de D. Francisca Xavier de Siqueira, sua esposa), todos eles representantes da tradicional elite paraense, tenham sido as mais superficiais.

45 AHU, Conselho Ultramarino, Pará, Cx. 87, doc. 7083. (Carta João Rodrigues de Castro para os oficiais do Senado da Câmara de Belém, Pará, 21 de novembro de 1780).

$46 \mathrm{AHU}$, Conselho Ultramarino, Pará, Cx.48, doc. 4400. Carta do sargento-mor Carlos Gemaque de Albuquerque, s/l, [1780].
} 
eram 36 escravos e, na época da moagem, seriam necessários mais 20 índios, sendo 10 homens e 10 mulheres. ${ }^{47}$

Um exemplo interessante sobre o uso mais especializado dos índios nos engenhos veio do relato do alferes auxiliar Francisco Antônio Pereira de Castro, que comprou o engenho de Santo Antônio da Mouraria no rio Moju, em 1777, com um só escravo, mestre oleiro e outros oficiais de olaria. Em 1780, já havia feito canaviais e cana de purgar, com 43 escravos capazes do serviço, entre homens e mulheres, ${ }^{48}$ mais oito índios e índias de soldada, concedidos pelo governador, além de outras oito índias fornecidas por três meses. Como resultado, tinha 59 pessoas capazes para o trabalho no engenho, apesar disso, indicava necessitar de mais 16 pessoas para a moedura. ${ }^{49}$

Com todo esse empenho, Francisco Antônio havia sido classificado como rico e aplicado. De fato, havia feito um investimento alto no soerguimento do engenho, mesmo não tendo mestre de açúcar, nem achar um que pudesse ser alugado. E o pouco açúcar que havia feito deveu-se ao empréstimo, por um tempo, de um índio chamado Pedro, que pertencia à casa de Álvaro Sanches Brito. De acordo com o alferes, Pedro foi utilizado somente pelo tempo da safra, de forma que Ihe pagou os dias conforme o seu merecimento, mandando-o depois "para a casa de seu amo". Entretanto, temendo Sanches Brito que o alferes tomasse o índio Pedro por todo o tempo, para além da safra, retirou-lhe o empréstimo do dito índio.

Por fim, em 1790, encontramos o alferes Francisco Antônio Pereira de Castro numa listagem feita no governo de Francisco de Souza Coutinho, em que foram arrolados todos os engenhos e engenhocas, para o controle da Fazenda Real dos impostos sobre as aguardentes fabricadas, donde se indicava a existência, no seu engenho, de 77 escravos e dois agregados, o qual havia fabricado 65 frasqueiras de aguardente, ${ }^{50}$ o que demonstra a sua persistência no funcionamento do engenho.

A manutenção dos engenhos reais não era fácil, muitos deles se encontravam decadentes nesse período. No relato encaminhado ao juiz ordinário, em 1790, dando conta do estado em que se encontrava o engenho de seu pai falecido, o capitão Hilário de Moraes Bittencourt informava que a reedificação do engenho, pelo qual se tornara responsável, Ihe tomaria muito da mão de obra que havia empregado em outras atividades. Além disso, demonstrava que a força do trabalho indígena se mantinha presente e necessária na agricultura, principalmente nas lavouras de cacau e arroz, às quais tinha se dedicado, com 36 escravos e aproximadamente 25 índios, entre adultos e menores. ${ }^{51}$ Temia, enfim, que todo

\footnotetext{
47 AHU, Conselho Ultramarino, Pará, Cx. 87, doc. 7076. (Carta Antônio José Landi para os oficiais do Senado da Câmara de Belém, Pará, 19 de novembro de 1780).

48 O mapa de 1778 indicava ter no engenho 45 escravos, sendo 38 homens ( 8 menores e 30 adultos) e 9 mulheres (1 menor e 8 adultas).

49 AHU, Conselho Ultramarino, Pará, Cx. 87, doc. 7077. (Carta de Francisco Antônio Pereira de Castro para os oficiais do Senado da Câmara de Belém, Pará, 19 de novembro de 1780).

50 APEP, Códice 352, fl. 72-74. Correspondência de Diversos com o governo do Pará, Listas dos moradores donos de propriedades do distrito do Rio Moju. [1790].

${ }^{51}$ APEP, Códice 473, documento 1, Correspondência de Diversos com o Governo do Pará, Carta Hilário de Moraes Bittencourt, 17 de agosto de 1790.
} 
esse esforço em manter o engenho funcionando lhe custasse o que havia já empreendido nas lavouras de cacau.

No mesmo período, havia uma forte pressão para o incremento das lavouras voltadas para exportação, como bem demonstra o governador do Pará, D. Francisco de Sousa Coutinho, nas informações prestadas ao secretário de Estado da Marinha e Ultramar, D. Rodrigo de Sousa Coutinho, em 1798, sobre os prêmios e incentivos aos lavradores no desenvolvimento de técnicas mais corretas no plantio das culturas. ${ }^{52}$ No ano anterior, a coroa havia ordenado que as informações sobre a população passariam a adotar um novo modelo, modificando substancialmente a natureza dos dados estatísticos. Foi introduzida a produção de outros arrolamentos que implicavam em novos elementos econômicos, além dos já anteriormente citados sobre a população, constando de mapas da importação, da exportação, das produções da capitania e dos preços correntes dos gêneros, dando início assim a uma nova modalidade de contar e controlar seus vassalos. ${ }^{53}$

\section{Considerações finais}

O desafio de examinar comparativamente um espaço geográfico complexo como o Estado do Grão-Pará e Rio Negro - que possuía, ao mesmo tempo, tanto características equivalentes quanto específicas - proporcionou-nos resultados que superaram as expectativas iniciais. No que se refere à composição social do estado, consideramos que a população não pode ser compreendia somente pela sua condição jurídica (livres e não livres), uma vez que o elemento indígena teve uma participação significativa na composição da população no período colonial; portanto, a apreciação da composição social levou em consideração livres, cativos $e$ índios.

Dessa feita, na análise comparativa foi observado que o Rio Negro, onde o índio teve presença majoritária durante todo o período setecentista, apresentou, no século seguinte, mudanças surpreendentes no perfil demográfico, revelando um crescimento expressivo da população livre, aumentando em mais de $40 \%$ de seu efetivo e aproximando-se da população indígena, enquanto o elemento cativo manteve-se pouco significativo no peso global da população da capitania. No Pará, a composição social demonstrou um equilíbrio entre as categorias no período setecentista, ainda que se verifique um aumento no componente cativo, compatível com a nova dinâmica do tráfico negreiro para a capitania e, em certa medida, com as possibilidades de reprodução endógena dos cativos que se sucederam na região. Notamos que a população livre e, principalmente, a indígena possuíam um peso considerável na composição social da capitania nesse período. Contudo, conforme nos indicam os dados

\footnotetext{
52 APEP, Códice 552, documento 44, fl. 633-34, Correspondência dos governadores com a Metrópole. Carta do governador ao secretário de Estado D. Rodrigo de Sousa Coutinho, Pará, 2 de março de 1798.

${ }^{53} \mathrm{AHU}$, Conselho Ultramarino, Piauí, Cx. 21, doc. 1094 (Ofício do governador do Piauí D. João de Amorim Pereira, para o secretário de Estado, D. Rodrigo de Sousa Coutinho, Oeiras do Piauí, 19 de agosto de 1798).
} 
levantados por Baena, o elemento livre no período seguinte viria a superar as demais categorias, constituindo-se em um elemento preponderante na população.

A presença do contingente indígena em ambas as regiões e, consequentemente, a importância como força de trabalho, pôde ser melhor observada nos estudos de caso apresentados. Os índios empregados nas fazendas e nos engenhos da região do Acará e Moju demonstram a utilização dos indígenas nas atividades agrícolas, a despeito das orientações do governo para que fossem aplicados nas coletas de drogas do sertão. Se, por um lado, a nova dinâmica do tráfico de escravos, secundada pela reprodução endógena dos cativos, contribuiu para a formação de uma importante força de trabalho cativa na região, emoldada em pequenos, médios e grandes plantéis escravos, por outro lado, as dificuldades causadas pelo fim da Companhia de Comércio do Grão-Pará e Maranhão, a despeito da continuidade do tráfico para a região, levaram os produtores paraenses a procurar os indígenas em soldada como um complemento à força de trabalho dos engenhos e das demais lavouras na capitania.

Por fim, é importante destacar que os resultados aqui apresentados, sistematizados a partir de fontes primárias, na sua maioria inéditas, desempenham um grande avanço nos estudos demográficos do Estado do Grão-Pará e Rio Negro, não somente por delinearem um perfil mais consistente da população da região, inexistente até agora, mas, sobretudo, por apontar dados empíricos mais seguros sobre os cálculos populacionais, que servirão certamente de referência às novas pesquisas, substituindo os antigos ensaios locais, cujas informações eram, o mais das vezes, imprecisas ou superestimadas.

Marcia Eliane Alves de Souza e Mello: Doutora em História Moderna pela Universidade do Porto (2002) e pós-doutorado pela Universidade Nova de Lisboa (2012). Foi vice-diretora do Instituto de Ciências Humanas e Letras (UFAM). É coordenadora do Núcleo de Pesquisa em Política, Instituições e Práticas Sociais (POLIS). Publicou o livro Fé e Império: As Juntas das Missões nas conquistas ultramarinas. Século XVII-XVII (2009). Atua na área de História do Brasil colonial.

Daniel Souza Barroso: Graduado em História pela Universidade Federal do Pará (UFPA, 2010), mestre em História pela Universidade Federal do Pará (UFPA, 2012) e doutorando em História Econômica na Universidade de São Paulo (FFLCH-USP), onde desenvolve investigação financiada pela Fundação de Amparo à Pesquisa do Estado de São Paulo (FAPESP). Integra a REFMUR (Espanha) e os grupos de pesquisa: Hermes \& Clio (FEA-USP) e RUMA (UFPA). 